EDUR • Educação em Revista. 2021; 37:e24481

DOI: http://dx.doi.org/10.1590/0102-469824481

https://creativecommons.org/licenses/by/4.0/

Dossiê: ESPAÇOS E ARQUITETURAS ESCOLARES

\title{
APRENDER A HABITAR LA ARQUITECTURA ESCOLAR DEL NUEVO ORDEN URBANO (DISTRITO FEDERAL, MÉXICO, 1932)
}

CARLOS ORTEGA ${ }^{1}$

ORCID: https://orcid.org/0000-0003-3916-9543

\begin{abstract}
Resumen: En 1932, el equipo de técnicos dirigido por el arquitecto funcionalista Juan O'Gorman desarrolló un proyecto de arquitectura escolar para las colonias populares del Distrito Federal (México). Una de esas escuelas, la escuela primaria Emiliano Zapata (actualmente reconocida como monumento artístico nacional), fue construida en una colonia fundada en el norte de la ciudad de México como parte de una estrategia de expansión urbana impulsada por empresarios y por el gobierno mexicano. Sus constructores pensaban que el edificio escolar era el medio para transformar a las clases populares de la sociedad mexicana e impulsar un orden urbano moderno. La arquitectura escolar funcionalista generó discusiones acaloradas entre ingenieros y arquitectos sobre el impacto de este tipo de edificios en el paisaje urbano y en el gusto de sus habitantes. Sin embargo, sus promotores aseguraban que eventualmente las clases populares aprenderían a habitar los nuevos edificios escolares y superarían el analfabetismo y la insalubridad que afectaban tanto a sus cuerpos como a sus mentes.
\end{abstract}

Palabras clave: Arquitectura escolar, Aprendizaje, Modernidad, Orden urbano, Juan O'Gorman.

\section{APRENDER A HABITAR A ARQUITETURA ESCOLAR DA NOVA ORDEM URBANA (DISTRITO FEDERAL, MÉXICO, 1932)}

Resumo: Em 1932, a equipe de técnicos liderada pelo arquiteto funcionalista Juan O'Gorman desenvolveu um projeto de arquitetura escolar para os bairros populares do Distrito Federal (México). Uma dessas escolas, a Escola Primária Emiliano Zapata (atualmente reconhecida como monumento artístico nacional), foi construída em um bairro fundado no norte da Cidade do México como parte de uma estratégia de expansão urbana promovida por empresários e pelo governo mexicano. Seus construtores pensaram que o prédio da escola era o meio de transformar

${ }^{1}$ Dirección de Difusión de Ciencia y Tecnología del Instituto Politécnico Nacional. Ciudad de México, México. $<$ cortegai@ipn.mx $>$ 
as classes populares da sociedade mexicana e promover uma ordem urbana moderna. A arquitetura funcionalista da escola gerasse discussões acaloradas entre engenheiros e arquitetos sobre o impacto desse tipo de construção na paisagem urbana e no gosto de seus habitantes. No entanto, seus promotores garantiram que, eventualmente, as classes populares aprenderiam a habitar os novos edifícios da escola e superariam o analfabetismo e a insalubridade que afetavam seus corpos e mentes.

Palavras-chave: Arquitetura escolar, Aprendendo, Modernidade, Ordem urbana, Juan O'Gorman.

\title{
LEARN TO INHABIT THE SCHOOL ARCHITECTURE OF THE NEW URBAN ORDER (FEDERAL DISTRICT, MEXICO, 1932)
}

\begin{abstract}
In 1932, the team of technicians led by the functionalist architect Juan O'Gorman developed a school architecture project for the popular neighborhoods of the Federal District (Mexico). One of those schools, the Emiliano Zapata Elementary School (currently recognized as a national artistic monument), was built in a neighborhood founded in the north of Mexico City as part of an urban expansion strategy promoted by businessmen and by the Mexican government. Its builders thought that the school building was the means to transform the popular classes of Mexican society and promote a modern urban order. Functionalist school architecture generated heated discussions between engineers and architects about the impact of this type of buildings on the urban landscape and on the taste of its inhabitants. However, its promoters assured that eventually the popular classes would learn to inhabit the new school buildings and they would overcome the illiteracy and unhealthiness that affected both their bodies and their minds.
\end{abstract}

Keywords: School Architecture, Learning, Modernity, Urban Order, Juan O’Gorman.

\section{INTRODUCCIÓN}

El propósito de este artículo es estimular la reflexión histórica sobre el aprendizaje del cuerpo humano para habitar un tipo de arquitectura escolar. Me refiero a la arquitectura escolar funcionalista promovida por el arquitecto Juan O'Gorman como parte del desarrollo de un orden urbano moderno en la primera mitad del siglo XX. Para tal efecto, emprendo inicialmente una caminata en retrospectiva hacia la colonia Industrial, en donde fue construida en 1932 la Escuela Primaria Emiliano Zapata, con el fin de ubicarla en una estrategia de colonización y neutralización política dirigida a dar un nuevo régimen al Distrito Federal (México). Posteriormente, me refiero a los esfuerzos de los intelectuales prácticos (principalmente ingenieros y arquitectos) para diseñar un nuevo orden urbano mediante una serie de actos técnicos, como son la fundación de una colonia moderna y la construcción de una escuela primaria funcionalista que permitieran erradicar del cuerpo de sus habitantes las afectaciones causadas por el viejo orden. Enseguida me concentro en la visión de esos mismos intelectuales sobre el aprendizaje o acostumbramiento de las clases populares para habitar una arquitectura escolar que, aseguraban, transformaría sus cuerpos afectados por el viejo régimen 
en cuerpos sanos física e intelectualmente. En el camino recurro a las ideas de André Le Breton, Zygmunt Bauman y Michel Serres para comprender la configuración del cuerpo humano en los proyectos desarrollados por los promotores de la modernización. En este artículo dejaré de referirme al Porfiriato (1880-1910), al periodo de la revolución (1910-1920) y al régimen posrevolucionario (de 1920 en adelante) como parámetros temporales. Hablaré de un viejo orden y de un nuevo orden porque la construcción de la modernidad ha sido un proceso de larga duración que atraviesa estos momentos, vinculándolos. Finalmente, el artículo también tiene como objetivo contribuir al discernimiento de las relaciones de moldeamiento mutuo de los sujetos - de su cuerpo- con la materialidad y la tecnología de la escuela, y de esta con la ciudad, a partir del estudio de la arquitectura escolar moderna dentro de la historia socio-cultural de la educación. $^{2}$

\section{CAMINAR HACIA EL OTRO EXTREMO}

La identificación de once escuelas, de las 21 que el equipo técnico encabezado por Juan O'Gorman diseñó en 1932 para varios pueblos y colonias populares del Distrito Federal, me llevó a un viaje en tres planos: uno documental (en la Planoteca del Archivo Histórico de la Ciudad de México), uno virtual (a través de Google Earth) y otro por las calles de la ciudad de México. El viaje en estos planos fue una experiencia corporal. Sin embargo, únicamente me referiré a la experiencia de caminar por las calles de la ciudad de México en la búsqueda de uno de los edificios escolares funcionalista, el de la Escuela Primaria Emiliano Zapata, declarada monumento artístico nacional en 2018 [Presidencia de la República, 2018: 69-70], o lo que quedara de éste.

Le Breton describió el acto de caminar con estas palabras:

Como todas las empresas humanas, incluso la de pensar, caminar es una actividad corporal, pero implica más que ninguna otra la respiración, el cansancio, la voluntad, el coraje ante la dureza de la ruta o la incertidumbre de la llegada, los momentos de hambre o de sed cuando no se encuentra ninguna fuente al alcance de los labios, ningún albergue, ninguna granja para aliviarle al viajero la fatiga de la jornada. [Le Breton, 2011: 31]

Sus palabras me hicieron recordar que el historiador, antes de haberse consagrado o resistiendo a la consagración que lo ancla al pedestal, es materia que se desplaza por el mundo, aunque su corporalidad -escindida en el dictum racionalista- no sea nombrada. Cada camino que

\footnotetext{
${ }^{2}$ En la historia de la educación en América Latina el cuerpo humano -y específicamente el cuerpo infantil- ha sido estudiado a partir de sus representaciones en publicaciones, libros y manuales escolares, la imposición de medidas coercitivas y la generación y aplicación de estrategias pedagógicas relativas a la educación física y la educación sexual. Las políticas, prácticas y discursos higienistas de los siglos XIX y XX, tendientes a la normalización de los cuerpos infantiles a través de la escuela pública, son el eje de su cobertura. Sin embargo, las relaciones de moldeamiento del cuerpo infantil con la materialidad de la escuela -el mobiliario, el vestuario, los materiales didácticos y el edificio- se encuentran generalmente implícitas, silenciosas, incorporadas [Julien y Roselin, 2005]. En el caso de la arquitectura escolar son menos quienes han abordado explícitamente estas relaciones de moldeamiento. Entre ellos destacan los vínculos de la arquitectura, la pedagogía y la higiene en la conformación de una intencionalidad regulatoria y disciplinaria de los inmuebles sobre la fisiología y las expresiones del cuerpo infantil [Bueno, 2009; Recio, 2009; González y Dorotinsky, 2010; Cordoví, 2012]. En este artículo, comprendido en lo que se ha llamado el giro material en la historiografía de la educación [Dussel, 2019], sugerimos que las relaciones del edificio escolar con el cuerpo humano son relaciones de moldeamiento mutuo que dan lugar a distintas posibilidades. 
inicia es un ensayo: sigue las huellas, duda, pide consejo, avanza, se aferra, se desvía, retrocede, se pierde, abandona la marcha, llega...

Así, un viernes de agosto de 2019 tomé la ruta que me llevaría a la escuela primaria Emiliano Zapata, ubicada en la colonia Industrial al Norte de la ciudad de México. Al salir de la estación Potrero del Sistema de Transporte Colectivo-Metro, agucé los sentidos para percibir las señales que me condujeran más de ochenta años atrás.

Cada paso me introdujo en una colonia fundada en 1926 a un costado de la calzada de Guadalupe, en la municipalidad de Guadalupe Hidalgo (actualmente Alcaldía de Gustavo A. Madero). En ese momento, la ciudad de México se expandía hacia los cuatro puntos cardinales del Distrito Federal. El fraccionamiento de las antiguas haciendas que rodeaban a la ciudad y la neutralización política de los gobiernos municipales fueron dos factores concatenados del ordenamiento urbano en la primera mitad del siglo XX, aunque, como señala Ariel Rodríguez Kuri [1996], su neutralización comenzó en los años ochenta del siglo anterior con la pérdida paulatina de facultades del Ayuntamiento de México.

El fraccionamiento de los terrenos baldíos de las haciendas para colonizarlos y urbanizarlos fue un negocio lucrativo en el que participaron empresarios y funcionarios públicos. Los terrenos de la hacienda de los Ahuehuetes, en donde fue fundada la colonia Industrial, fueron adquiridos por una sociedad tripartita conformada por el ingeniero Alberto Pani, quien fungía como Secretario de Hacienda del gobierno de Plutarco Elías Calles y estaba dedicado a la reorganización del sistema financiero nacional, el banquero Agustín Legorreta, directivo del Banco Nacional de México S.A., y el ingeniero Roberto Rodríguez. Entre los tres pagaron 120 mil pesos por 120 hectáreas de la hacienda [Pani, 2003: 303].

El proyecto original, denominado "Colonia Industria S.A.", consistía en el acondicionamiento y fraccionamiento del terreno para la instalación de pequeñas fábricas. Pronto -como lo cuenta Pani en su autobiografía publicada en 1945- el proyecto fue reemplazado por una empresa de mayor provecho para quienes la llevaron a cabo: el fraccionamiento del terreno en lotes pequeños para la construcción de casas [Pani, 2003: 303].

De acuerdo con el urbanismo de matriz funcionalista, el sistema de loteo, geométrico y estandarizado, era una manera de prolongar las ciudades ordenadamente. Le Corbusier, cuyos planteamientos tecno-políticos fueron promovidos por jóvenes arquitectos mexicanos desde la década de 1920, propuso reemplazar el viejo trazo de las ciudades, irregular y confuso, por grupos sucesivos de casas que serpentearan a lo largo de avenidas diagonales en consonancia con el espíritu de la producción en serie de la época industrial [Le Corbusier, 1925: 47]. Según la doctrina funcionalista de Le Corbusier [1925], la imposición de este orden urbano traería bienestar para los habitantes de cualquier metrópoli.

En concordancia con estos planteamientos, la empresa urbanizadora promovió a la colonia Industrial como un lugar para vivir bien e higiénicamente, sin lujos, pues contaba con calles pavimentadas con asfalto y macadam petrolizado, servicio de luz, drenaje, agua potable y transporte público, especialmente una estación del tranvía eléctrico [Imágenes 1 y 2]. La fundación de este tipo de colonias coincidía con la atribución del gobierno del Distrito Federal de favorecer la construcción de casas higiénicas para la habitación de las clases humildes, aunque bajo la modalidad del alquiler [Poder Ejecutivo Federal, 1928-1929, artículo 24, IX], y era un incentivo para el aumento de la población y el ensanchamiento de la ciudad gracias a su infraestructura sanitaria y los servicios urbanos con los que contaba [Departamento de la Estadística Nacional (DEN), 1935: 20]. 
Imagen 1. Publicidad de La Colonia Industrial, 1930.

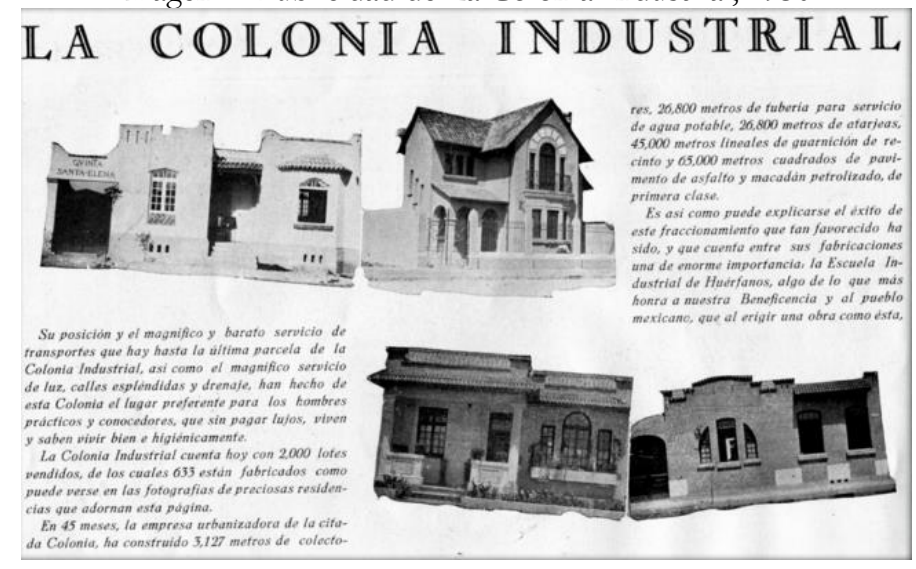

Fuente: El Universal.

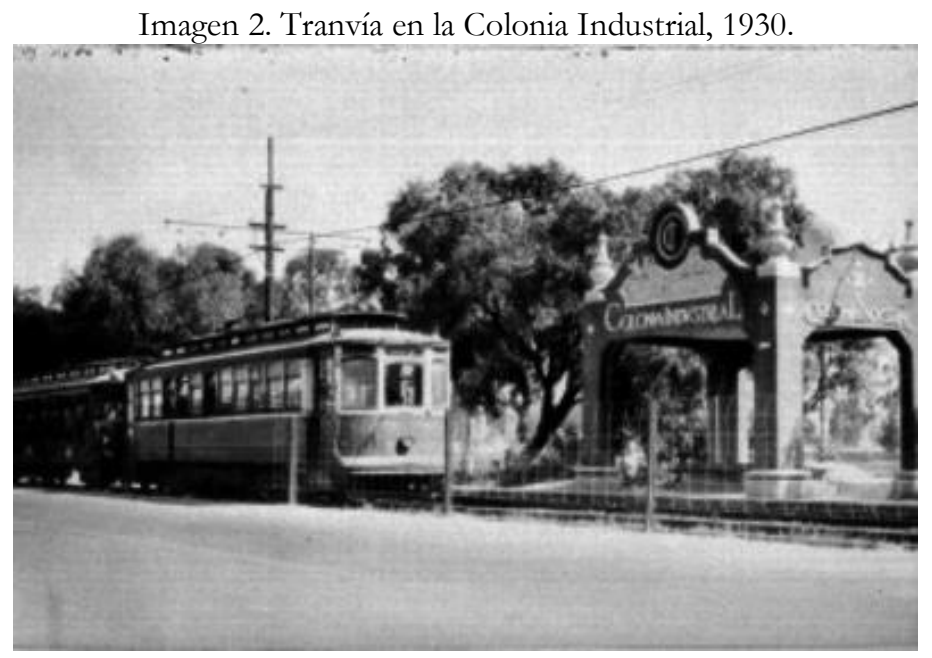

Fuente: Fototeca del INAH, México.

Continuando con el testimonio autobiográfico de Pani, en la colonia Industrial se construyeron, en los años de 1926 a 1945, más de tres mil seiscientas casas, cuatro parques, un mercado, una escuela y un cine [Pani, 2003: 304]. Pero una fotografía de 1955, resguardada en la fototeca del Instituto Nacional de Antropología e Historia, da cuenta de la existencia de una habitación precaria, construida con láminas de madera, en una calle de la nueva colonia [Imagen 3]. 
Imagen 3. Choza en una calle de la Colonia Industrial, 1955.

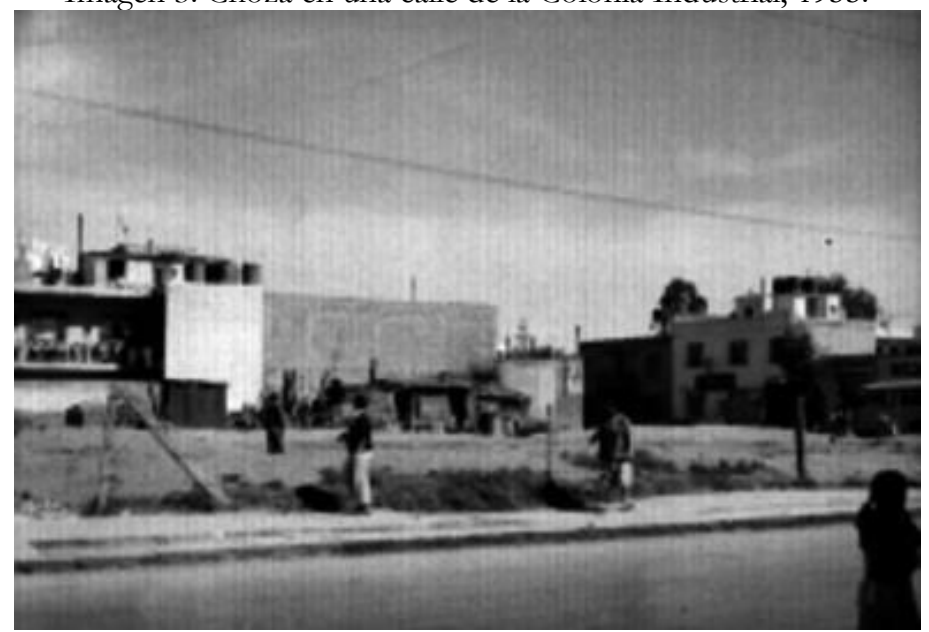

Fuente: Fototeca del INAH, México.

La existencia de una choza representaba la permanencia del caos, la ausencia de forma en medio del nuevo orden urbano. En 1933 dos jóvenes arquitectos funcionalistas, Juan Legarreta y Álvaro Aburto, observaban la existencia de unas cuantas ciudades modernas, con avenidas grandes, edificios y monumentos, en un país cuyo pueblo habitaba mayoritariamente en cuartos redondos y jacales con techo de zacate y paredes de carrizo [SAM, 1933]. Para ambos arquitectos, esas habitaciones reflejaban la vida desmaterializada de un pueblo que no podía superar a la naturaleza - peligrosa por insalubre- porque padecía la falta de una intervención técnica en su modo de vida.

Al momento de su fundación, la colonia Industrial pertenecía al municipio de Guadalupe Hidalgo, pero una serie de reformas emprendidas por el gobierno federal reemplazaron a los gobiernos municipales (cuyas autoridades eran elegidas por los habitantes de la localidad) por delegaciones del Departamento del Distrito Federal (DDF).

La Ley Orgánica de 1928-1929 estipuló que el gobierno de las delegaciones correspondía al Jefe del DDF, quien lo ejercería a través de delegados nombrados por él de acuerdo con el Presidente de la República. Cada delegado contaba con el auxilio de subdelegados que lo representaban en las poblaciones que no eran cabecera de delegación y con un consejo consultivo conformado por los "principales intereses de la localidad" [Poder Ejecutivo Federal, 1928-1929, capítulo X]. El delegado tenía la facultad de elegir entre las asociaciones de comerciantes, industriales, propietarios de bienes raíces, inquilinos, campesinos, profesionistas, empleados públicos y privados, trabajadores y madres de familia, a aquellas que representaban dichos intereses [Poder Ejecutivo Federal, 1928-1929, capítulo X].

La reforma del régimen político del DF tenía como objetivo gobernar a una ciudad que no dejaba de ensancharse debido al crecimiento de los poblados que la rodeaban y a la formación de nuevas colonias por la intervención de múltiples intereses [DEN, 1935]. Vicente Lombardo Toledano, quien no estaba de acuerdo con la desmunicipalización del Distrito Federal, reconocía que la gobernabilidad era un asunto técnico y político común a las grandes ciudades del mundo, toda vez que su crecimiento había generado inevitablemente una crisis en su sistema de gobierno y en su organización administrativa [Lombardo, 1928: 17].

Visto de esa manera me atrevo a sugerir que la reforma pretendía evitar, mediante una nueva organización política de la sociedad capitalina, que sucediera cualquier cosa; por 
ejemplo, otra revolución, la cual era vista por intelectuales de distintas tendencias como sinónimo de desorden o catástrofe ocasionada por la irrupción de unas clases populares insatisfechas e irracionales. Para Juan O'Gorman, las clases populares eran un pueblo "falto de raciocinio elemental" que carecía de habitaciones cómodas e higiénicas [Sociedad de Arquitectos Mexicanos (SAM), 1934: 15]. Para otro arquitecto, Manuel Amábilis, se trataba de un pueblo rebelde con aspiraciones desorientadas [SAM, 1934: 9].

Esta reforma neutralizó políticamente al DF durante casi nueve décadas, hasta que sus habitantes pudieron elegir nuevamente a sus alcaldes en 2018. Así, la expansión de la ciudad y su control político se concatenaron en un proyecto que pretendía dar un nuevo orden a una ciudad dinámica que en 1930 era reconocida como uno de los principales centros culturales, comerciales y de negocios de América y del mundo. Para apuntalarla como una ciudad moderna, ordenada, higiénica y armónica, el gobierno federal decretó la Ley de Planificación y Zonificación del Distrito Federal en 1933, según la cual el DF se dividiría en zonas clasificadas de acuerdo con las funciones y usos para los que estarían destinadas [Poder Ejecutivo Federal, 1933: 5-7], entre estas las de tipo residencial, comercial e industrial.

Como parte del reordenamiento impuesto al DF, la colonia Industrial pasó de la jurisdicción de la Delegación de Guadalupe Hidalgo (desaparecida en 1931) a la Delegación de Azcapotzalco [Poder Ejecutivo Federal, 1931, artículo 7].

En el censo de 1930, la Delegación de Azcapotzalco era la segunda más poblada del $\mathrm{DF}$, con 40 mil habitantes y uno de los mayores índices de población urbana (60.5\%), muy abajo del millón de habitantes de la ciudad de México (cuya población fue considerada como totalmente urbana). La mayoría de los habitantes de la delegación, casi $50 \%$, se concentraba en la villa de Azcapotzalco, y el resto vivía en ranchos, haciendas y pueblos que no superaban los 300 habitantes. Podemos suponer que la mayoría de los jefes de familia (hombres) no eran propietarios del lugar en donde vivían. En el DF, la norma era habitar una casa de alquiler [DEN, 1935].

Azcapotzalco compartía con la Delegación de San Ángel el tercer lugar en la tasa de analfabetismo del DF porque 32\% de sus habitantes mayores de 10 años no sabían leer ni escribir. En cambio, la ciudad de México y Coyoacán tenían el índice de analfabetismo más bajo del DF, 20\% y 27\% respectivamente. En otras delegaciones como Cuajimalpa, Iztapalapa y Milpa Alta, cuya población era mayoritariamente rural, la tasa de analfabetismo era de 47\%, superando el 70\% entre las mujeres mayores de 30 años. En el caso de Azcapotzalco, el analfabetismo entre las mujeres mayores de 10 años superaba al de los hombres por más de seis puntos porcentuales [DEN, 1935].

El mismo censo nos ofrece una imagen de la colonia Industrial distinta de aquella promovida por los fraccionadores del terreno en donde fue fundada cuatro años atrás. El rubro relativo a la población distribuida por localidades no incluye el nombre de la colonia Industrial. En cambio, proporciona el número de habitantes (278) de la primera y segunda secciones de la Hacienda de los Ahuehuetes. La segunda sección, habitada por 81 personas, correspondía a los terrenos ocupados por la nueva colonia [DEN, 1935].

De esta manera, la colonia Industrial, cuyas calles llevaban el nombre de algunas de las principales industrias de México, era apenas un enclave, quizá todavía un proyecto de la expansión de la ciudad sobre un territorio configurado por ranchos, haciendas y pueblos. A un costado de una de sus calles, llamada la Fundidora de Monterrey, el gobierno del DF construyó en 1932 un edificio funcionalista para la escuela primaria Emiliano Zapata (ícono del agrarismo revolucionario), con capacidad para albergar a 1000 niños. La Secretaría de Educación Pública argumentaba que la construcción de escuelas como ésta vendría a solucionar el déficit de 
inmuebles ocasionado por el aumento apresurado de la población del Distrito Federal [Secretaría de Educación Pública (SEP), 1932: 55].

Sin embargo, resalta la disparidad entre la capacidad de la escuela (mil niños), en una delegación cuya tasa de analfabetismo superaba el 30\%, y el número de habitantes de la colonia Industrial (menos de cien). Pero atender a la población escolar de la zona (no únicamente de la colonia en nacimiento) y estimular la colonización de los terrenos de la Hacienda de los Ahuehuetes, podrían ser dos objetivos articulados. Una escuela moderna, amplia e higiénica era parte de la infraestructura urbana y de los servicios públicos que los fraccionadores y los gobiernos mencionaban para estimular el poblamiento de los territorios recientemente ocupados, ganados al mudo rural.

La caminata terminó frente a la escuela primaria Emiliano Zapata, cuyo edificio fue divido posteriormente para albergar otra escuela primaria (la Escuela Primaria Jesús Romero Flores). Ahí pude observar lo que queda del edificio de 1932: la fachada, el muro ciego, los albañales, las aulas y la planta [Imágenes 4 y 5]. En el interior de la escuela Emiliano Zapata se encuentran, acusando un grave deterioro, los murales de Pablo O'Higgins sobre el trabajo, la lucha obrera y los problemas sociales.

Imagen 4. Escuela Primaria Emiliano Zapata, 1933.

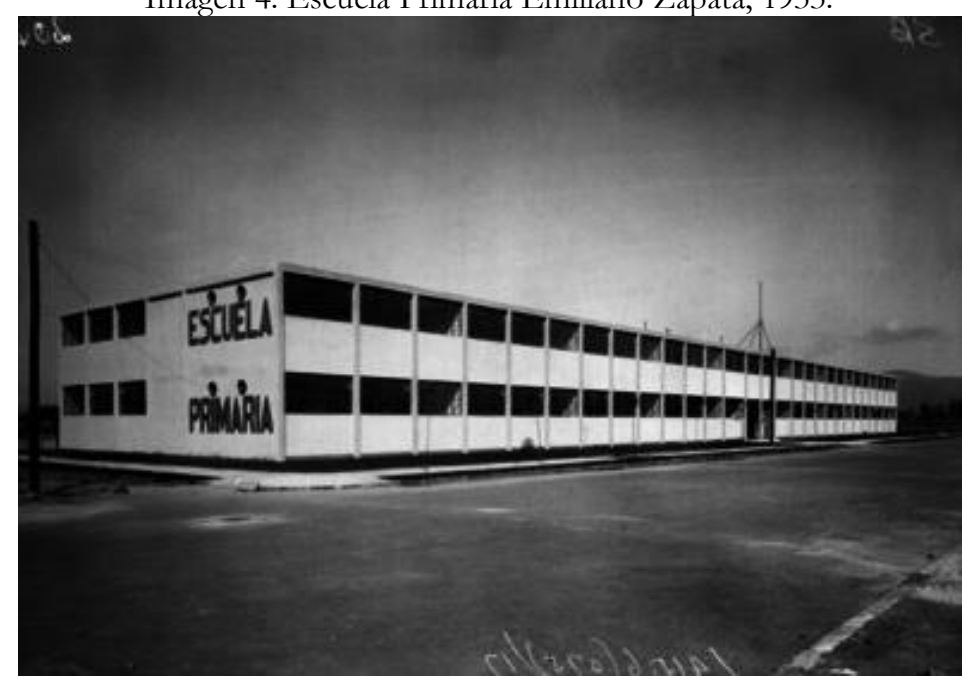

Fuente: Fototeca del INAH, México. 
Imagen 5. Fachada lateral de la Escuela Primaria Emiliano Zapata, 2019.

[Actualmente corresponde a la escuela Jesús Romero Flores]

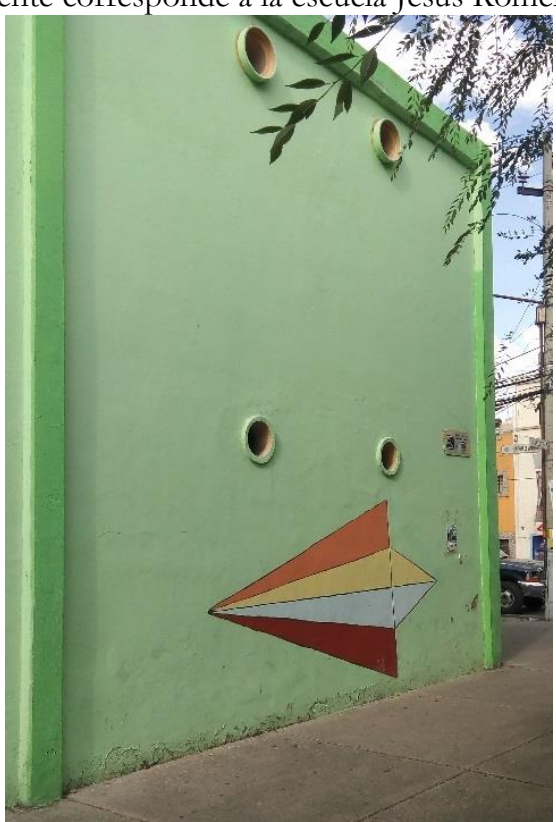

Fuente: Fotografía del autor.

A partir de estos indicios intento imaginar al inmueble, siguiendo la doctrina funcionalista que orientó su diseño, como una máquina, como una herramienta desarrollada para satisfacer la necesidad de habitaciones económicas, cómodas e higiénicas de los futuros pobladores del proyecto de la Colonia Industrial S.A. Mientras lo hago, recurro a las ideas de Bauman [2015: 38-39] sobre los diseños en la historia de la era moderna como retratos de una realidad futura distinta de la conocida por los diseñadores, quienes no contaban, por tratarse precisamente del futuro, cómo sería el mundo que emergería en el otro extremo de sus esfuerzos de construcción, extremo en el que yo me encuentro parado.

\section{SUPERAR LASTRES DE MUGRE E IGNORANCIA}

En 1932 la colonia Industrial y la escuela primaria Emiliano Zapata plasmaban el proyecto de un orden futuro construido sobre la base del progreso técnico. La técnica, definida entonces por el filósofo madrileño José Ortega y Gasset [2004] como el esfuerzo dedicado a diseñar aquello que no existe en la naturaleza del hombre (asignándole un carácter masculino), era vista como el medio para superar una realidad que disgustaba y atemorizaba a intelectuales que se desempeñaban como intelectuales de estado y funcionarios públicos, y quienes deseaban encaminar a las clases populares por la ruta de una modernidad de la que ellos eran promotores [Fiorucci y Rodríguez, 2018].

Dicho proceso demandaba la actuación de un tipo de intelectual práctico que asumiera la tarea de construir el nuevo orden social mediante la transformación de la naturaleza, aplicando las leyes de la ciencia, como afirmó el ingeniero Agustín Aragón al iniciar el siglo XX [Aragón, 1900: 73]. Ese intelectual práctico era el ingeniero, cuya formación técnica y comportamiento viril lo avalaban como constructor de la modernidad, a diferencia de los 
arquitectos sentimentales o artistas, quienes -según Le Corbusier [1925] y Juan O’Gorman [SAM, 1933]- representaban al viejo régimen y eran incapaces de emprender la nueva tarea.

En los proyectos de reforma urbana, la modernidad fue planteada como la superación de un régimen caduco cuyos resabios se encontraban en cada esquina del Distrito Federal, obstruyendo la construcción del nuevo orden urbano. Por ese motivo la labor de los ingenieros consistía en corregir a través de sus obras los efectos del antiguo régimen (el desorden y el caos), y en erradicar su subsistencia en el nuevo orden urbano con el fin de evitar una nueva catástrofe o una revolución encabezada por los desposeídos y analfabetas.

En este sentido la modernidad, como sugiere Bauman, es un proceso de construcción de un nuevo orden permanentemente enfrentado al pasado que se desea superar. Pero el nuevo orden, en tanto que es un orden futuro, es un anhelo que sus promotores alimentan de manera compulsiva y adictiva porque la supresión del viejo régimen parece una tarea inacabable [Bauman, 2015: 45-46].

El ingeniero Alberto Pani, quien desde la primera década del siglo XX se comprometió a prestar sus servicios técnicos para formar un nuevo orden, denunció los claroscuros del antiguo régimen. Como agente del nuevo régimen opinaba que el progreso material y cultural, en ocasiones aparente, del Distrito Federal durante el viejo orden, contrastaba con la existencia abundante de especímenes correspondientes a las etapas históricas más primitivas de la civilización [Pani, 2003: 201]. En el mismo sentido, Félix Palavicini, otro ingeniero sumado a la causa del nuevo régimen, describió en 1916 a la ciudad de México como una capital en la que se elevaban suntuosos palacios de mármol y granito, sin arte, y por cuyas calles asfaltadas caminaban los sujetos creados por el viejo régimen: "los indios harapientos y piojosos" [Secretaría de Cultura, 2016:702].

Pani juzgaba que las acciones del antiguo régimen en materia de educación popular y salud pública, ámbitos que consideraba propios de las sociedades civilizadas, habían sido superficiales e ineficientes y se preguntaba qué efectos benéficos podía tener una escuela pobremente dotada de elementos técnicos y materiales sobre los hábitos y el carácter de los niños del bajo pueblo ante la "poderosa influencia atávica y la más poderosa aun del ambiente malsano e inmoral que aspiran, en las casas de vecindad... en todos los instantes de su vida y desde que nacen" [Pani, 2003: 111-112].

En resumen, el analfabetismo y la insalubridad de las clases populares eran el sino del viejo régimen y su herencia al nuevo orden. Una herencia que un joven arquitecto, Juan O'Gorman, deseaba erradicar mediante una arquitectura técnica, ingenieril, que pudiera contar con el respaldo del gobierno federal.

En 1933, O'Gorman observaba un desorden absoluto en la arquitectura de la ciudad de México como resultado de una forma irracional de proceder basada en el gusto y los sentimientos tanto de los propietarios (quienes conformaban una minoría) como de los arquitectos (quienes se encontraban al servicio de esa minoría). Acusaba que en una calle era posible encontrar un edificio clásico, uno Luis XI, uno seudo-colonial y uno modernista, y comparaba las casas de las nuevas colonias de la clase media, como la Hipódromo, con un cuadro anarquista sin orden ni ciencia [SAM, 1934: 11-13].

Para O'Gorman, del otro lado de esa ciudad estaba el pueblo mexicano; una mayoría a la que describió como ignorante, carente de educación y de raciocinio elemental, y cuya vida era, en consecuencia, pobre, miserable y trágica [SAM, 1934]. Ese pueblo habitaba en pocilgas, en casas mal hechas, chuecas e imperfectas.

Ante esa situación, para O’Gorman era evidente que el Distrito Federal requería de la intervención de una arquitectura técnica que satisficiera -mediante procedimientos medibles 
y estandarizados- las necesidades básicas de la mayoría de sus habitantes. Una arquitectura que liberara al pueblo de sus principales enemigos, la naturaleza y el fanatismo, al proporcionarle mejores habitaciones. Una arquitectura moderna que le permitiera superar lo que a su juicio eran "lastres de mugre e ignorancia" [SAM, 1934: 15].

Para los ingenieros y arquitectos modernizadores el antiguo régimen seguía vivo en la urbe, en su arquitectura histórica y monumental y en las costumbres primitivas, en el comportamiento desregulado, en los hábitos insalubres y en la vida desmaterializada del pueblo (eufemismo con el que se referían a los pobres). Para estos intelectuales prácticos, la fundación de la colonia Industrial y la construcción de la escuela primaria Emiliano Zapata eran actos técnicos que permitirían corregir los efectos funestos del antiguo régimen y apuntalar un nuevo orden urbano. A su juicio, la materialización de la colonia y de la escuela, y de otras colonias y otras escuelas semejantes, transformaría positivamente a los habitantes del Distrito Federal. Al intervenir en los niños mediante la arquitectura escolar, tenían en mente el diseño de un sujeto futuro. Para la Secretaría de Educación Pública se trataba de un plan socializador de la educación urbana y de intensificar el esfuerzo cultural en los campos [SEP, 1932: 56].

En general, la construcción de escuelas formaba parte de los proyectos de planificación del Distrito Federal. En 1935, el recientemente formado Comité del Plano Regulador del DF concluyó que uno de los problemas a resolver era la distribución adecuada de las escuelas tomando en cuenta la densidad de la población escolar, la accesibilidad de la zona y la disposición de espacios libres, jardines y campos de juego [Comité del Plano Regulador, 1935: 64]. Después de todo, como afirmaba el arquitecto Carlos Contreras, promotor de dichas iniciativas de planificación, se trataba de hacer de la ciudad de México "un modelo de limpieza y de orden" [Contreras, 1928: 4]. Sin embargo, a pesar de todos estos deseos, los intelectuales prácticos no podían tener la certeza de cómo sería el sujeto que emergería en el otro extremo de sus esfuerzos de construcción.

\section{CREAR EL GUSTO, ACOSTUMBRAR EL CUERPO}

En la década de 1920 Le Corbusier publicó Vers une architecture, un programa tecnopolítico que orientó los proyectos modernizadores de arquitectos funcionalistas como Juan O'Gorman. Para ellos, entre quienes también se encontraban Juan Legarreta y Álvaro Aburto, la arquitectura técnica, también llamada arquitectura funcional, era el medio que permitiría formar un nuevo orden social. Sin embargo, como reconocía Le Corbusier [1925], faltaba crear el estado de espíritu de construir y habitar casas en serie en los arquitectos y más aún, en una población persuadida por la arquitectura de viejo cuño. En otras palabras, los arquitectos funcionalistas tenían la tarea de formar el gusto y la disposición de habitar aquellas casas construidas a la manera de la producción industrial. En Europa, intelectuales como Ortega y Gasset [1992] y Walter Benjamin [2003] estimaban, desde posiciones filosóficas diferentes, que se trataba de una época nueva para el arte, la de la producción industrial, que introduciría cambios en la percepción o sensibilidad de los sujetos, tanto de los artistas como del público.

La arquitectura de las nuevas habitaciones tenía una función formativa: entrenar a sus habitantes, educar sus sentidos, acondicionar su cuerpo, acostumbrarlo a la nueva realidad material y a los otros cuerpos con quienes la habitaría cara a cara en un territorio acotado por paredes de tabique y concreto armado. Los arquitectos modernizadores deseaban lograr con sus nuevos diseños aquello que los diseños anteriores no pudieron: superar los lastres y atavismos que aquejaban a las clases populares. Su meta era transformar a los pobres, siguiendo la ruta bio- 
política del higienismo [Suárez, 2005], en seres física y moralmente sanos a través de una arquitectura técnica.

O’Gorman expuso ante sus colegas de la Sociedad de Arquitectos Mexicanos que su propósito era dar higiene física y moral al pueblo a través de la construcción económica y estandarizada de edificios escolares cómodos, con ventanas grandes y suficientes baños de regadera [SAM, 1934]. De acuerdo con el proyecto elaborado por O'Gorman, la escuela primaria Emiliano Zapata, construida con concreto armado y tabique en terrenos de la colonia Industrial, albergaría a mil niños en veinte salones ubicados en dos plantas. El edificio tendría biblioteca, comedor, enfermería, sala de juntas, dirección, habitación para el conserje, WC y baños de regadera para mujeres y para hombres [magen 6]. Las instalaciones eléctricas y sanitarias, el drenaje, el suministro de agua potable y la ventilación de las aulas mediante albañales dispuestos sobre la fachada lateral de la escuela (en el muro ciego), garantizarían el funcionamiento adecuado del edificio y la salud de sus habitantes como lo dictaba el canon funcionalista [SEP, 1932].

Imagen 6. Plano de la Escuela Primaria Emiliano Zapata, 1932.

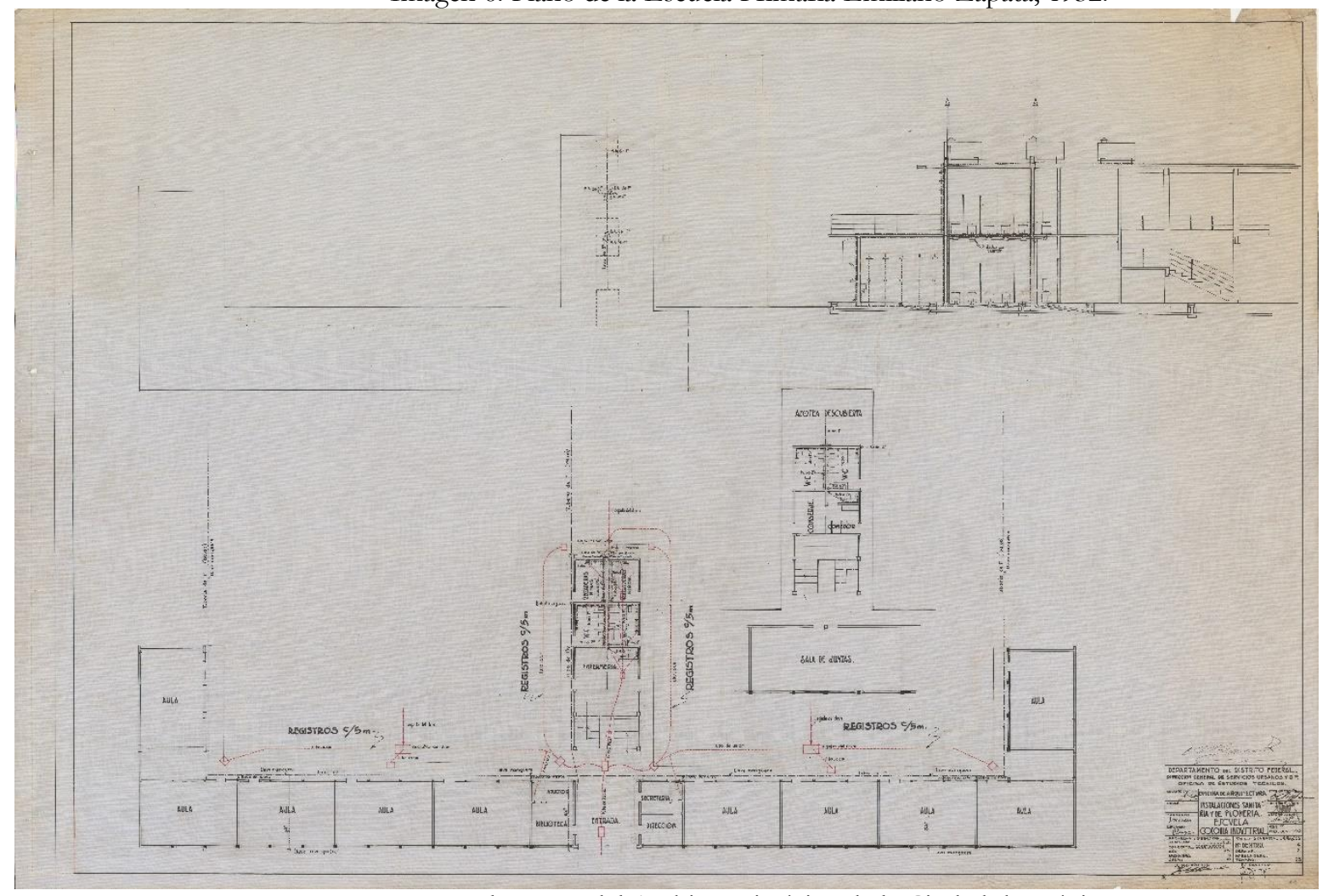

Fuente: Planoteca del Archivo Histórico de la Ciudad de México.

Otros arquitectos e ingenieros, considerados como representantes de la "vieja estructura espiritual", tenían una percepción negativa de la arquitectura técnica y de los edificios escolares diseñados por O'Gorman.

El arquitecto Manuel Amábilis rechazaba cualquier intento de someter a la arquitectura a un proceso de producción estandarizado, "a la estrecha rigidez de un trazado geométrico preestablecido" cuyo resultado solo podía ser la construcción de edificios sin belleza [SAM, 1934: 8]. Con él coincidía el ingeniero Raúl Castro Padilla, quien opinaba que los edificios escolares de O’Gorman eran ejemplos de una arquitectura de funcionamiento peristáltico que 
únicamente expresaban pauperismo [SAM, 1934: 29]. Para Castro Padilla, el trabajo de O'Gorman carecía de imaginación y esfuerzo porque se había limitado a copiar elementos arquitectónicos estandarizados por mercaderes e industriales y a pensar en cubos o paralepípedos con agujeros y rejas de cárcel [SAM, 1934: 29-30].

De igual forma, el arquitecto Silvano Palafox opinaba que el obrero, el campesino y el proletario se sentirían incómodos, infelices e insatisfechos con ese tipo de habitaciones [SAM, 1934: 40], las cuales -según Federico Mariscal- eran una muestra de la retrogradación de la arquitectura al instinto gregario de la horda o del clan [SAM, 1934: 27]. Palafox equiparó al habitante de las nuevas construcciones -a las que él y sus colegas calificaban como resultado de aspiraciones irracionales estimuladas por la destrucción del viejo régimen- con un salvaje que al escuchar la novena sinfonía de Beethoven "saldría dando alaridos, pues se sentiría profundamente lastimado con semejante música” [SAM, 1934: 40]

Otros arquitectos reconocían el papel formativo de la arquitectura de O'Gorman, a pesar de no compartir plenamente su orientación funcionalista. Manuel Ortiz Monasterio afirmaba que en general el papel social de la arquitectura era educar, moralizar y mejorar a la sociedad [SAM, 1934: 20]. En particular, opinaba que los edificios escolares de O'Gorman, junto con la obra plástica de los pintores muralistas, desempeñaban un papel importante en la preparación de "una generación fuerte, sana, sencilla y alegre, capaz de emocionarse con la verdad, el bien y la belleza, y de forjar nobles ideales que la eleven sobre las torpes y duras concepciones de la materia" [SEP, 1932: 66].

O’Gorman no desconocía la función formativa de su arquitectura, y, en una réplica hacia los críticos del funcionalismo, afirmó, haciendo una analogía entre los nuevos diseños y el lenguaje, que las personas se acostumbrarían a oír bonito lo que al principio parece feo. Para la Secretaría de Educación Pública la aceptación de esta arquitectura era una cuestión de tiempo [SEP, 1932: 64].

\section{OTRAS POSIBILIDADES}

Acostumbrase a la nueva arquitectura escolar implicaba la incorporación de su materialidad. Que el desplazamiento y la disposición del cuerpo, de los sentidos, en las habitaciones cómodas e higiénicas que sustituirían a los jacales, chozas y pocilgas, llegaran a ser actos inconscientes porque la inconciencia, como propone Michel Serres [2011], es olvidarse de la materialidad del cuerpo y de la relación de moldeamiento mutuo que establece con las cosas y los objetos. En el cuerpo, el aprendizaje consiste en que:

Cadenas complicadas de posturas se incorporan tan fácilmente en sus músculos, huesos y articulaciones que sepulta en un simple olvido la memoria de esa complejidad. Y después, como sin saberlo, reproduce esas series de posiciones con mayor rapidez de lo que las asimiló [Serres, 2011: 82].

Pero este aprendizaje silencioso tiene su balance, su contrapeso, en la producción inventiva, en la variación de los gestos corporales. Serres asume que el cuerpo también aprende a poderlo casi todo [Serres, 2011: 53]. De tal manera que el cuerpo de las clases populares, en el que los intelectuales prácticos deseaban intervenir a través de la arquitectura técnica para

erradicar lastres y atavismos con el fin de construir un nuevo orden urbano, podía acostumbrarse 
a las escuelas funcionalistas de O’Gorman y aprender a evadir los muros construidos en serie por la modernidad.

En 1933 el pintor de origen estadounidense, Pablo O’Higgins, representó esos cuerpos en los muros de la escuela primaria Emiliano Zapata. Siguiendo el programa políticopedagógico del muralismo mexicano [Lear, 2019], O’Higgins, quien fue discípulo de Diego Rivera, plasmó su deseo de conducir a los niños trabajadores por una ruta que los liberara de la explotación y la ignorancia gracias a la orientación de un dirigente obrero, moreno, sano, viril, con gesto adusto y ataviado de overol, y quien les ofrece un libro rojo e indica el camino de la manifestación proletaria que deben seguir.

Pero en "La realidad del trabajo y sus luchas" y en "La vida y los problemas sociales", el gesto de los niños varía [Imágenes 7 y 8]. Mientras dos niños trabajan en la producción del vidrio, uno completamente desnudo y otro con el torso descubierto, otro, afuera de una mina, fija su atención en la parte del libro rojo que su mentor -el dirigente obrero- le indica. Otros más, un niño y una niña (la única mujer en las dos escenas), sugieren otras posibilidades. Aunque el dirigente obrero les extiende un libro rojo con la mano derecha y con la izquierda señala una manifestación proletaria, ambos niños desvían la mirada. No atienden al obrero, ni al libro ni a la manifestación. Dirigen su mirada hacia afuera del cuadro, en sentido opuesto a las indicaciones de su mentor, porque otra cosa los atrae.

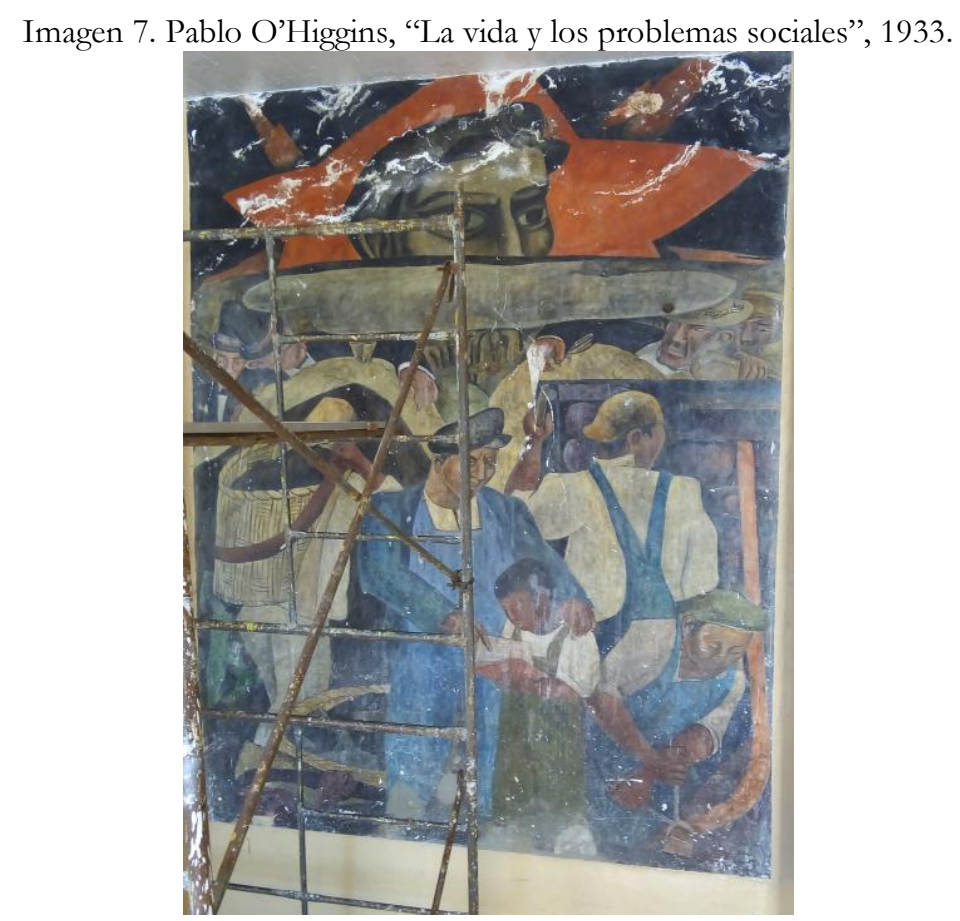

Fuente: Fotografía del autor. 
Imagen 8. Pablo O’Higgins, “La realidad del trabajo y sus luchas”, 1933.

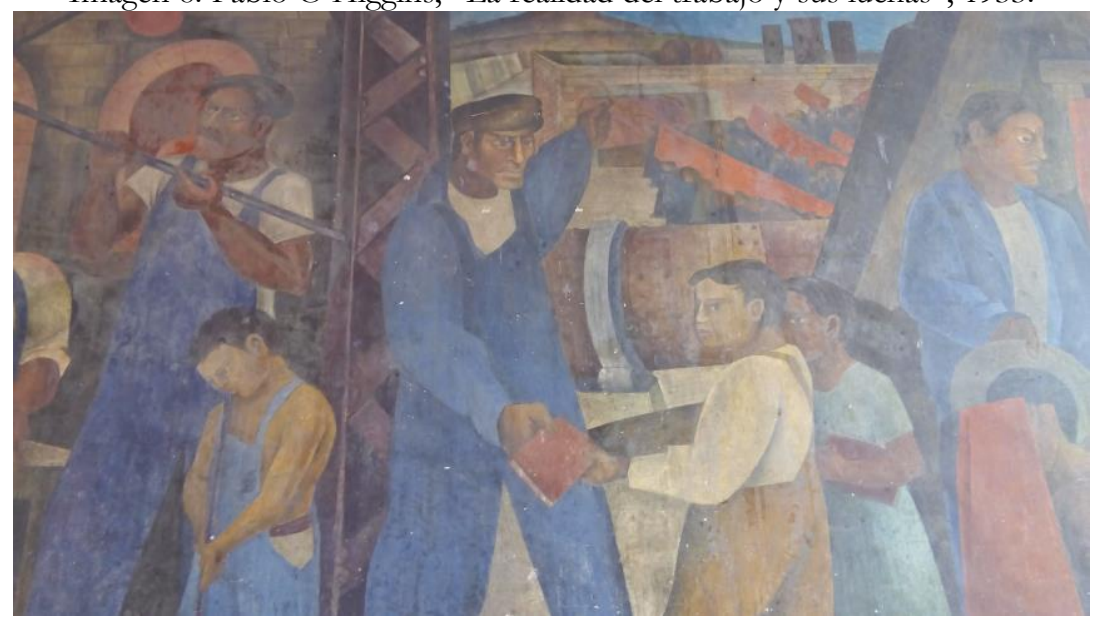

Fuente: Fotografía del autor.

Yo los observo desde el mundo que emergió en el otro extremo de los esfuerzos dedicados a construir, ocho décadas atrás, una ciudad moderna, una colonia industrial, una escuela funcionalista y un cuerpo sin lastres ni atavismos, física e intelectualmente sano. Un mundo en el que, a pesar de ese esfuerzo compulsivo de los modernizadores de ayer, continuado por los modernizadores de hoy, el desorden sigue manifestándose. Para erradicarlo, como en un cuento de nunca acabar, seguimos diseñando intervenciones técnicas, arquitectónicas y pedagógicas.

\section{CONSIDERACIONES FINALES}

Como propuse inicialmente, el artículo pretendía estimular la reflexión histórica sobre el aprendizaje del cuerpo humano para habitar un tipo de arquitectura escolar y contribuir al discernimiento de las relaciones de moldeamiento mutuo de los sujetos con la tecnología y la materialidad de la escuela (particularmente de su arquitectura y de esta con la ciudad). La fundación de la Colonia Industrial, en 1926, y la construcción de la Escuela Primaria Emiliano Zapata, en 1932, fueron dos hechos que me permitieron exponer cómo la escuela pudo haber incidido en el ensanchamiento urbano al estimular la colonización de los terrenos eriazos de las antiguas haciendas que rodeaban a la ciudad de México, y cómo pensaban, los promotores del nuevo orden urbano, que la escuela contribuiría a la transformación de sus habitantes al acostumbrarlos a habitar la nueva realidad arquitectónica que la escuela plasmaba. Sin embargo, reconozco que el artículo aportó una perspectiva parcial: los proyectos, las ideas y las opiniones de unos cuantos intelectuales comprometidos con el diseño arquitectónico y el desarrollo de un orden urbano moderno en la primera mitad del siglo XX, y para quienes los actos técnicos de este tipo eran un medio para erradicar los lastres del antiguo régimen, la insalubridad y el analfabetismo, de la vida de unas clases populares a las que veían con menosprecio. En todo momento indiqué que las cosas podían suceder de manera diferente a la planeada por dichos intelectuales, como lo sugieren la fotografía de la choza de láminas de madera, en la colonia Industrial, y el gesto divergente de los niños del mural de Pablo O’Higgins, en la escuela Emiliano Zapata, pero faltan estudios que nos brinden el testimonio, la percepción, la experiencia de habitar la nueva arquitectura escolar de parte de aquellos sujetos para quienes estaba destinada, lo que constituye un desafío metodológico para la historia de la arquitectura escolar. 


\section{REFERENCIAS}

Aragón, A. (1900). Función de los Ingenieros en la vida social contemporánea. El Arte y la Ciencia, revista mensual de Bellas Arte e Ingeniería, 2 (5), 73-74.

Bauman, Z. (2015). Vidas desperdiciadas. La modernidady sus parias. Paidós.

Benjamin, W. (2003). La obra de arte en la época de su reproductibilidad técnica, Editorial Itaca.

Bueno, Maria de Fátima Guimarães (2009). A história da educação: a cidade, a arquitetura escolar e o corpo, Cadernos do CEOM, 21 (28), 243-278.

Comité del Plano Regulador (1935). Informe que rinde el Comité del Plano Regulador integrado por el arquitecto Carlos Contreras, ingeniero José A. Cuevas y arquitecto Carlos Tarditi, a la Comisión de Planificación del Distrito Federal. Planificación, órgano de la Asociación Nacional para la Planificación de la República Mexicana, 3 (3-6), 59-72.

Contreras, C. (1928). Plano Regulador del Distrito Federal. Planificación, órgano de la Asociación Nacional para la Planificación de la República Mexicana, 1 (13), 4.

Cordoví Núñez, Yoel (2012). Cuerpo, pedagogía y disciplina escolar en Cuba: dispositivos de control desde los discursos higienistas (1899-1958). Tzintzun. Revista de Estudios Históricos, (56), 93-136.

DEN (1935). Censo de Población. 15 de mayo de 1930. Distrito Federal, Departamento de la Estadística Nacional.

Dussel, Inés (2019). La cultura materia de la escolarización: reflexiones en torno a un giro historiográfico, Educar em Revista, 35 (76), 13-29.

Fiorucci, F. y Rodríguez, L. (2018). Intelectuales de la educación y el Estado: maestros, médicos y arquitectos. Universidad Nacional de Quilmes.

González Mello, Renato y Dorotinsky Alperstein, Deborah (coordinadores) (2010). Encauzar la mirada. Arquitectura, pedagogía e imágenes en México 1920-1950, México, Instituto de Investigaciones Estéticas, UNAM.

Julien, Marie Pierre y Rosslin, Céline (2005). La culture matérielle, París, La Découverte.

Lear, J. (2019). Imaginar el proletariado. Artistas y trabajadores en el México revolucionario, 1908-1940. Libros Grano de Sal.

Le Breton, D. (2011). Caminar: un elogio. Un ensayo sobre el placer de caminar, La Cifra Editorial.

Le Corbusier (1925). Vers une architecture, Les Éditions G. Crès et Cie.

Lombardo Toledano, V. (1928). "La supresión del Ayuntamiento Libre en el Distrito Federal", en: Planificación, órgano de la Asociación Nacional para la Planificación de la República Mexicana, tomo 1, número 9, pp. 17-24.

Ortega y Gasset, J. (1992). La deshumanización del arte e Ideas sobre la novela. Velázquez-Goya, Editorial Porrúa.

Ortega y Gasset, J. (2004). Meditación de la técnica y otros ensayos sobre ciencia y filosofía, Madrid, Alianza Editorial.

Pani, A. (2003). Apuntes autobiográficos (II volúmenes) Senado de la República.

Poder Ejecutivo Federal (1931). Decreto que modifica la Ley Orgánica del Distrito y Territorios Federales. Diario Oficial, Órgano del Gobierno Constitucional de los Estados Unidos Mexicanos, LVXVII (47), 1-6.

Poder Ejecutivo Federal (1928-1929). Ley Orgánica del Distrito y los Territorios Federales. Diario Oficial, Órgano del Gobierno Constitucional de los Estados Unidos Mexicanos, LI-LII (474). 
Poder Ejecutivo Federal (1933). Ley de planificación y zonificación del Distrito Federal y territorios de la Baja California. Diario Oficial, Órgano del Gobierno Constitucional de los Estados Unidos Mexicanos, LXXVI (14), 5-7.

Presidencia de la República (2018). Decreto por el que se declara monumento artístico la Escuela Primaria Emiliano Zapata. Diario Oficial de la Federación, 782 (14), 69-70.

Recio, Carlos Mario (2009). Escuela, espacio y cuerpo, Revista Educación y Pedagogía, 21 (54), 129139.

Rodríguez Kuri, A. La experiencia olvidada. El Ayuntamiento de México: política y gobierno, 1876-1912. El Colegio de México, UAM-Azcapotzalco.

SAM (1934). Pláticas de arquitectura, 1933. Sociedad de Arquitectos Mexicanos.

Secretaría de Cultura (2016). Diario de los debates del Congreso Constituyente 1916-1917 (tomo 1). Secretaría de Cultura, Instituto Nacional de Estudios Históricos de las Revoluciones de México.

SEP (1932). Escuelas primarias 1932 en Arias Montes, V. (Coordinador) (2005). Juan O'Gorman. Arquitectura escolar 1932. UNAM, UAM-Azcapotzalco.

Serres, M. (2011). Variaciones sobre el cuerpo. Fondo de Cultura Económica.

Suárez y López Guazo, L. (2005). Eugenesia y racismo en México, Universidad Nacional Autónoma de México.

Submetido: $04 / 08 / 2020$

Aprovado: $14 / 10 / 2020$ 